\title{
Contrexéville - Bulgnéville
}

Liaison Vittel - A 31, seconde tranche

Jean-Charles Brénon

\section{(2) OpenEdition}

Édition électronique

URL : http://journals.openedition.org/adlfi/8869

ISSN : 2114-0502

Éditeur

Ministère de la culture

Référence électronique

Jean-Charles Brénon, « Contrexéville - Bulgnéville », ADLFI. Archéologie de la France - Informations [En ligne], Lorraine, mis en ligne le 01 mars 2001, consulté le 03 mai 2019. URL : http:// journals.openedition.org/adlfi/8869

Ce document a été généré automatiquement le 3 mai 2019.

(C) Ministère de la Culture et de la Communication, CNRS 


\title{
Contrexéville - Bulgnéville
}

\author{
Liaison Vittel - A 31, seconde tranche
}

\author{
Jean-Charles Brénon
}

Identifiant de l'opération archéologique : F1388200100006

Date de l'opération : 2001 (EV)

1 Cette seconde tranche de diagnostic (voir Bilan scientifique régional 1998:112, et Bilan scientifique régional 1999 : 117) a permis de réaliser un transect archéologique ouest-est long de $6,2 \mathrm{~km}$ et large de $70 \mathrm{~m}$ à $80 \mathrm{~m}$ en moyenne. Le tracé coupe le relief de cuesta situé entre les cours supérieurs de la Meuse et du Madon et rencontre des terrains majoritairement boisés où la formation superficielle a été fortement érodée. Cette érosion explique, sans doute, l'absence d'indices et de vestiges structurés pour les périodes préhistorique et protohistorique. Ainsi, le potentiel archéologique détecté est davantage en rapport avec les époques historiques ancienne, moderne et contemporaine.

2 La période gallo-romaine est documentée sur le finage de la commune de Contrexéville aux lieux-dits Champ Calot, Remivaux, Le Grand Hachu par trois tronçons rectilignes appartenant à un axe viaire orienté ouest-est. La voie présente les caractéristiques morphologiques d'une route secondaire romaine, large de3m à4m maximum, qui s'élargit suivant un écartement de $7 \mathrm{~m}$ à $8 \mathrm{~m}$ là où la déclivité du terrain entraîne une accumulation des eaux de ruissellement. Elle est alors bordée de fossés latéraux qui assurent le drainage. Sur le secteur Le Grand Hachu en périphérie de la voie, un espace funéraire a été mis en évidence à travers quatre structures en fosse. Les indices anthropiques exhumés sont caractéristiques d'un lieu où la pratique funéraire de la crémation est en usage. Sous toutes réserves, une datation est proposée pour la seconde moitié du II ${ }^{\mathrm{e}}$ siècle de notre ère sur la base d'un élément céramique peu caractéristique.

3 Après un hiatuschronologique d'environ seize siècles, la digue d'un étang actuellement asséché, a été localisée sur la commune de Bulgnéville au lieu-dit La Goulotte. $L^{\prime}$ 'aménagement, attesté dès le XVIII ${ }^{\mathrm{e}} \mathrm{s}$. par son positionnement sur la carte de Cassini, est 
probablement en lien avec une activité piscicole. Les deux coupes stratigraphiques effectuées dans la digue n'ont pas permis de préciser la fonction et la chronologie de cette installation.

4 Des vestiges plus contemporains des $\mathrm{XIX}^{\mathrm{e}} \mathrm{s}$. et $\mathrm{XX}^{\mathrm{e}} \mathrm{s}$., liés à l'exploitation de gîtes minéraux, ont été directement ou indirectement touchés par le projet routier. L'extraction du gypse à Contrexéville, Champ Calot, a laissé plusieurs puits de forage et deux excavations à ciel ouvert associées à des plates-formes de rejet des stériles. À Bulgnéville, La Grande Tranchée, l'exploitation concerne une mine de houille et son réseau de galeries, qui sont situés sous la future route entre $15 \mathrm{~m}$ et $20 \mathrm{~m}$ de profondeur. La fouille préventive de l'axe viaire et de la nécropole est nécessaire. Les résultats permettront peut-être de caractériser les relations existant entre ces vestiges et l'établissement rural gallo-romain du Petit Hachu.

BRÉNON Jean-Charles

\section{INDEX}

operation Fouille d'évaluation (EV)

Thèmes : acquisition de ressource naturelle, céramique gallo-romaine, digue, drainage, érosion, étang, exploitation agricole, gypse, incinération, mine, pisciculture, pratique funéraire, site d'extraction, voie

Index chronologique : Empire romain, ép. contemporaine, Temps Modernes

Index géographique : Lorraine, Vosges (88), Contrexéville

\section{AUTEURS}

JEAN-CHARLES BRÉNON 